\title{
Surface Composite Fabrication of Aluminium Alloy Using Friction Stir Processing
}

\author{
Authors \\ M.Chaitanya Kumar ${ }^{1}$, D.Santharao ${ }^{2}$ \\ ${ }^{1}$ P.G.Student, BVC Engineering College, Odalarevu, Amalapuram, A.P, India \\ ${ }^{2}$ Associate Professor, Department of Mechanical Engineering, B.V.C. Engineering College, Odalarevu, \\ Amalapuram, A.P, India \\ Corresponding Author \\ M.Chaitanya Kumar \\ Email: chaitanyakummar@gmail.com ${ }^{1}$
}

\begin{abstract}
:
Friction stir processing (FSP), which is a solid-state micro-structural modification technique using friction heat and stirring action, has recently attracted attention for making aluminium alloys with an excellent specific strength, and its studies have been actively performed. This process is the outgrowth of the basic principle of friction stir welding (FSW), and the mechanical properties of the Friction Stir Processed material are improved due to the grain refinement of the micro-structural modification. Friction stir processing (FSP) is best suited for preparation of surface composites and surface modification. In this project, aluminium alloy base surface composites were fabricated with Titanium Boride micro powder on an aluminium alloy plate using FSP under different process parameters. The mechanical properties like tensile strength, hardness and microstructures have been evaluated and the results are compared. From this investigation it is found that mechanical properties are improved with higher speeds and lower feeds.

Keywords: Friction stir processing, Aluminium alloys, Composites, Properties
\end{abstract}

\section{INTRODUCTION}

Friction stir welding and its variation of FSP, is a solid-state joining and surface modification technique were invented at The Welding Institute of UK in 1991. Application of FSW showed great promise in joining many ferrous and non-ferrous alloys that were joined by using conventional welding techniques with great difficulty. The convenience of the FSW as a joining technique has been demonstrated in a number of studies. Recently a new processing technique Friction stir processing (FSP) was developed by Mishra et al for microstructural modification and fabrication of metal matrix composites are based on the principles of FSW.

In this case, a rotating tool with pin and shoulder was inserted into a single piece of material, for localized micro structural modification. The FSP caused intense plastic deformation, material mixing, and thermal exposure, resulting in significant micro structural refinement, densification, and homogeneity of processed zone. This technique has been successfully applied in the production of fine grained structure and surface composite.

The schematic of FSP is shown in Figure1. To process a sheet by friction stir, a specially designed cylindrical tool is used which while rotating is plunged into the selected area. The tool has a small diameter pin with a concentric larger diameter shoulder. When the tool is plunged into the sheet, the rotating pin contacts the surface and friction between the sheet surface and the shoulder rapidly heats and softens a small column of metal, enabling the transverse movement of the tool through the material. During FSP, the area to be processed and the tool are moved relative to each other such that the tool traverses, with overlapping passes, until the 
entire selected area is processed to a desired (fine) grain size.

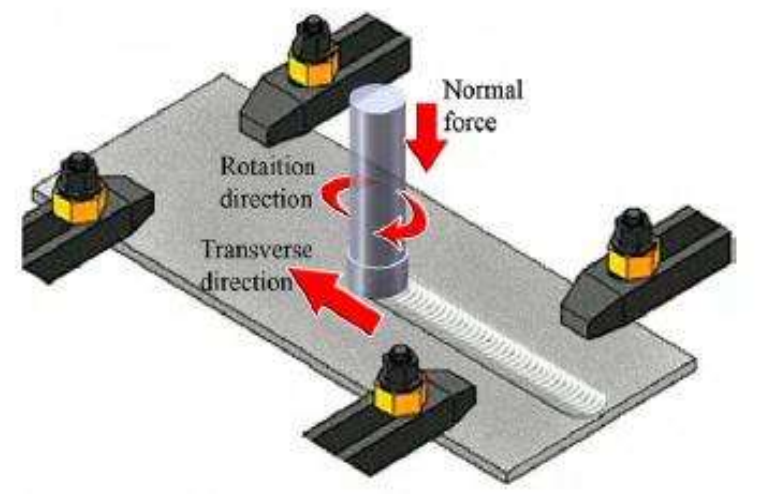

Fig. 1

Friction stir processing (FSP) is a recent technology for surface modification and developing surface composites and this friction stir processing can be done to aluminium alloys. Aluminium and its alloys mostly used in automotives and aerospace industries because of its low density and high strength to weight ratio. The addition of reinforcements (Tib) raised performance limits of the aluminium alloys and matrix makes brittle. R.S.Mishra et al, demonstrated that the FSP is a versatile technique with a comprehensive function for the fabrication, processing and synthesis of materials.

In this work, aluminium alloy base surface hybrid composites were fabricated with Titanium-boride micro powder on an aluminium plate using FSP with higher speeds and lower feeds. The mechanical properties like tensile strength, hardness and microstructures have been evaluated and the results are compared.

\section{EXPERMENTATION}

The base material employed in this study is a $100 * 80 * 6 \mathrm{~mm}$ aluminium alloy plate was utilized for making the surface composites with Tib micro powder. The chemical composition of the base material is given in Table1. Tib2 particles with various ratios were used as reinforcements. The reinforcement particles have the similar average particle size of $1 \mu \mathrm{m}$.

\begin{tabular}{|c|c|c|c|c|}
\hline 0.682 & 0.215 & 0.748 & 0.462 & 0.146 \\
\hline $\mathrm{Cr}$ & $\mathrm{Ti}$ & $\mathrm{Ga}$ & $\mathrm{Al}$ & \\
\hline 0.015 & 0.017 & 0.009 & 97.3 & \\
\hline
\end{tabular}

A square groove was made with dimensions of 1 $\mathrm{mm}$ width and $5 \mathrm{~mm}$ depth tangent to the pin in the advancing side, which is $1 \mathrm{~mm}$ far away from the centre line of the tool rotation on the Aluminium plate. The schematic of aluminium alloy plate for FSP is shown in Fig. 2.

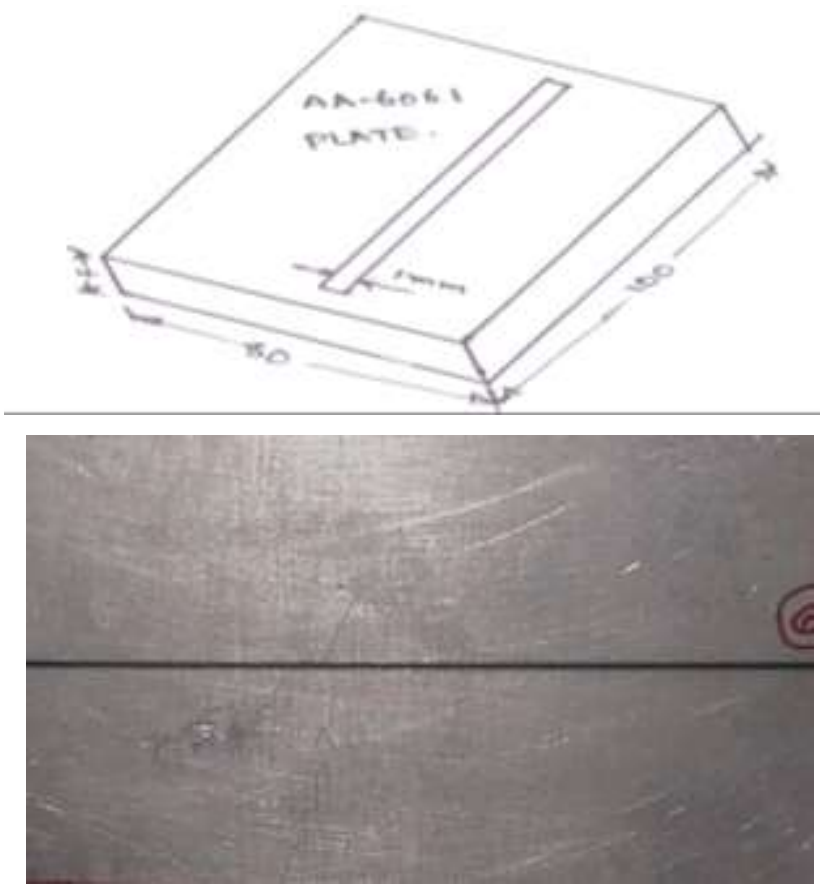

Fig. 2

High speed steel tool (HSS) having square pin profile with shoulder diameter of $18 \mathrm{~mm}$, pin diameter of $4 \mathrm{~mm}$ and $4 \mathrm{~mm}$ height was used.

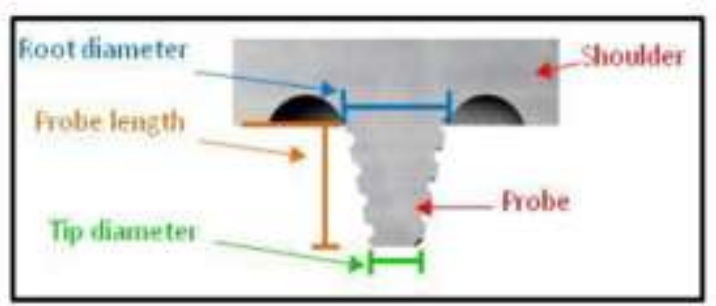

The selected ratios of reinforcement mixture i.e. $\mathrm{Tib}_{2}$ particle mixture is packed in the groove. The groove opening was initially closed by means of the tool which has shoulder without pin to avoid the escapement of reinforcement particles from groove while processing. The experiments were carried out on a vertical milling machine (Make HMT $7.35 \mathrm{kw}$, $10 \mathrm{hp}, 3000 \mathrm{rpm})$, shown in figure3, as per the following speeds and feeds shown in Table 2.

Table 2

Table 1

\begin{tabular}{|l|l|l|l|l|}
$\mathrm{Si}$ & $\mathrm{Cu}$ & $\mathrm{Mg}$ & $\mathrm{Fe}$ & $\mathrm{Zn}$ \\
\hline
\end{tabular}




\begin{tabular}{|c|c|c|c|}
\hline Exp No & $\begin{array}{c}\text { Rotational } \\
\text { speed } \\
\text { (RPM) }\end{array}$ & $\begin{array}{c}\text { Feed } \\
(\mathbf{m m} / \mathbf{m i n})\end{array}$ & Load(N) \\
\hline 1 & 600 & 20 & 5 \\
\hline 2 & 600 & 30 & 6 \\
\hline 3 & 600 & 40 & 7 \\
\hline 4 & 800 & 20 & 6 \\
\hline 5 & 800 & 30 & 7 \\
\hline 6 & 800 & 40 & 5 \\
\hline 7 & 1200 & 20 & 7 \\
\hline 8 & 1200 & 30 & 5 \\
\hline 9 & 1200 & 40 & 6 \\
\hline
\end{tabular}

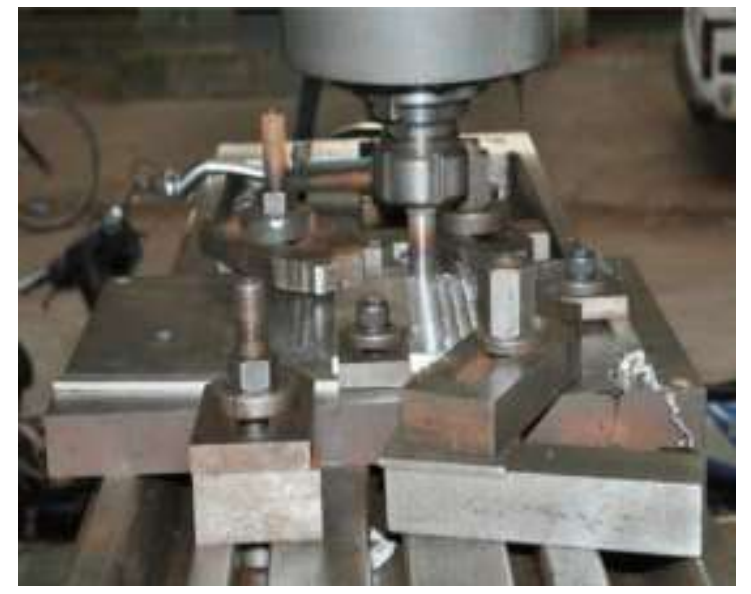

Fig. 3

After FSP, the specimens were cut from the stir zone using wire-cut EDM then micro structural observations were carried out at the cross section of nugget zone (NZ), shoulder, HAZ and TMAZ of surface hybrid composites normal to the FSP direction by optical microscope $(\mathrm{OM})$. The specimens were mechanically polished and etched with Keller's reagent ( $2 \mathrm{ml} \mathrm{HF}, 3 \mathrm{ml} \mathrm{HCL}, 20 \mathrm{ml}$ $\mathrm{HNO}_{3}$ and $175 \mathrm{ml} \mathrm{H}$

The Scanning Electron Microscope (SEM) was also utilized for measuring the reinforcement particles size of surface hybrid composites. Micro hardness tests were carried out at the cross section of NZ of surface hybrid composites normal to the FSP direction. Samples were tested with a load of $10 \mathrm{~g}$ and duration of $15 \mathrm{~s}$ using a Vickers digital micro hardness tester.

The tensile specimens were taken from the surface hybrid composites normal to the FSP direction to the required dimensions. The schematic sketch of tensile specimen is shown in Fig.4. The tensile test is carried out on a computer controlled universal testing machine (make: Associated Scientific Engg.
Works, New, Max 5 Ton) at a cross head speed of $0.5 \mathrm{~mm} / \mathrm{min}$.

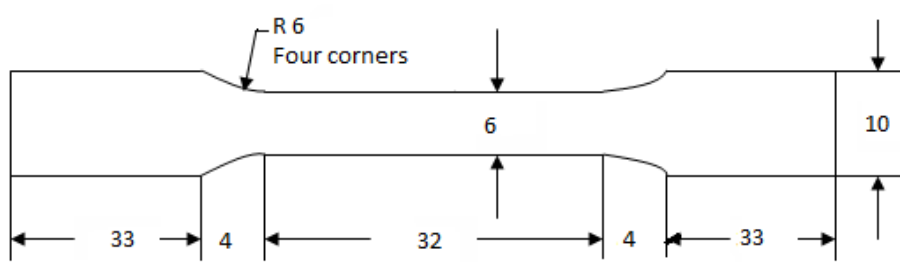

Fig. 4

\section{RESULTS AND DISCUSSIONS}

The surface hybrid composites were successfully fabricated via FSP as shown in Fig. 5. There were no imperfections such as cracks, voids on the surface. It also revealed that the top surface appears to be smooth and fine quality with almost no depressions. The cross sectional micrograph of the aluminium surface hybrid composite is shown in Fig.6. It revealed clearly different regions on the surface hybrid composite after FSP.

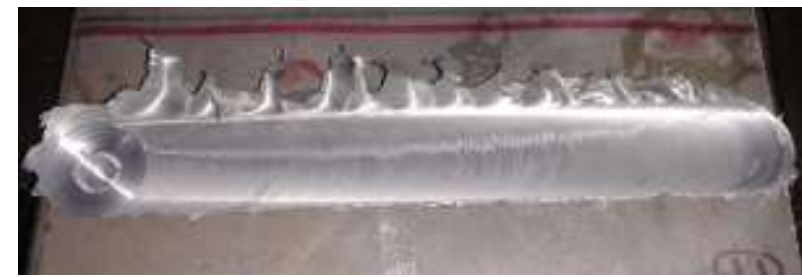

Fig.5 Macrograph of FSP zone of surface hybrid composite

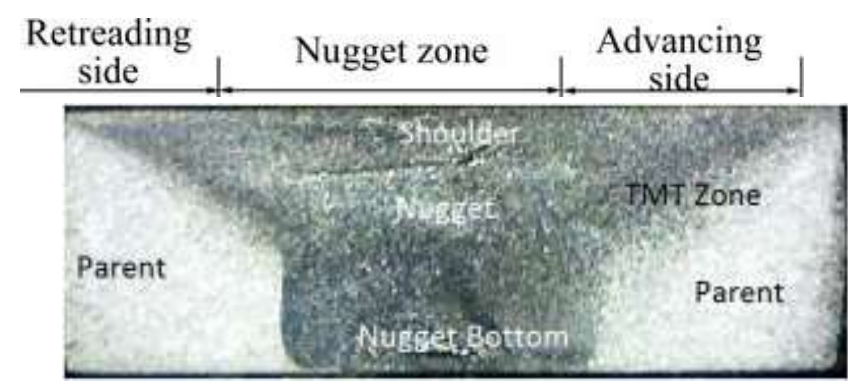

Fig.6 Cross-sectional Micrograph of surface hybrid composite

\subsection{Microstructure Evaluation}

The reinforcement particles were observed to be dispersed uniformly within the $\mathrm{NZ}$ due to the existence of dynamic stirring of the rotating tool during the FSP. And also received optical micrographs of surface hybrid composites and shows the structure at high tensile strength occurs at $800 \mathrm{rpm}$ are shown in Fig.7.Figure8 shows the SEM structures of various points in $\mathrm{NZ}$ of surface hybrid composite. It is seen that the scratches are 
less in composite compared with base metal

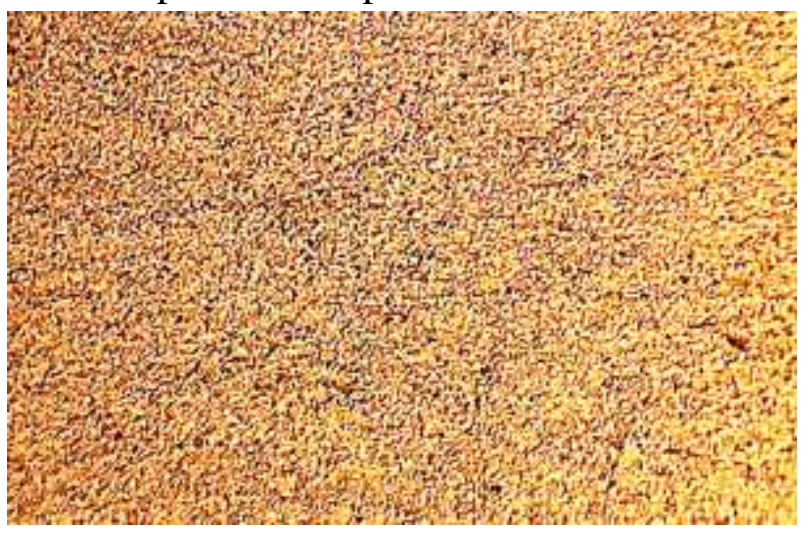

because of the presence of Tib2 in the composite.

Fig. 7 - Optical Microstructures of the surface hybrid composite with Titanium boride powder:

(a) Base metal

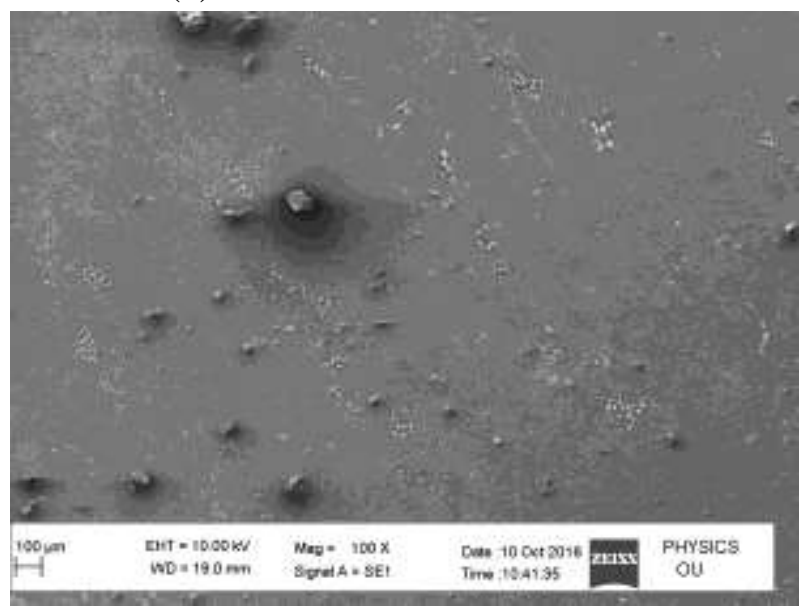

(b) Tib at $800 \mathrm{rpm}$ as-received aluminium alloy

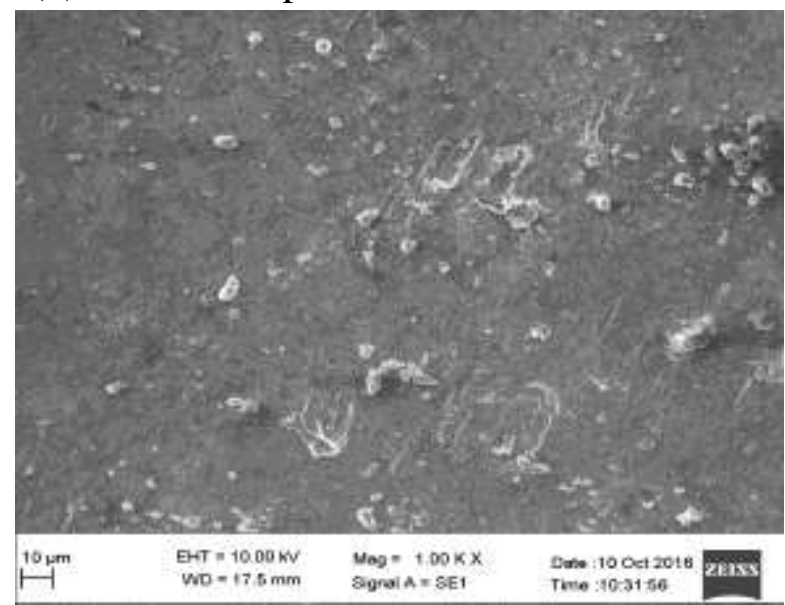

Fig. 8 - SEM Micrographs of the surface hybrid composites with Tib2 powder:

(a) Base metal

\subsection{Micro hardness survey}

The micro hardness of composites was measured and presented in Fig.9. As compared with the average hardness of about HV 106 of matrix material, the hardness value of surface hybrid composite were increased due to the presence of Tib2 reinforcement particles. In the current investigation, the Al-Tib2 composite showed higher hardness value due to the presence of soft Tib2 micro powder. The higher hardness of the surface hybrid composite is mainly due to reinforcement particles. And also observed that, as the rotational speed increases, the micro-hardness decreases. This is due to the high heat generation that causes matrix softening which decreases the micro hardness. This softening of the NZ resulted in coarsening and dissolution of strengthening precipitates in the aluminium matrix which occurs especially in heat treatable aluminium alloys. The optimum micro hardness value was obtained at the rotational speed of $800 \mathrm{rpm}$. This was due to fact (b) Tib at $800 \mathrm{rpm}$ as-received aluminium alloy that at $800 \mathrm{rpm}$ the tool shoulder supplied enough heat input and shear force to make the reinforcement particles more easily wrapped by the softening metal and rotated with FSP tool which results in well separation and distribution in the nugget zone.

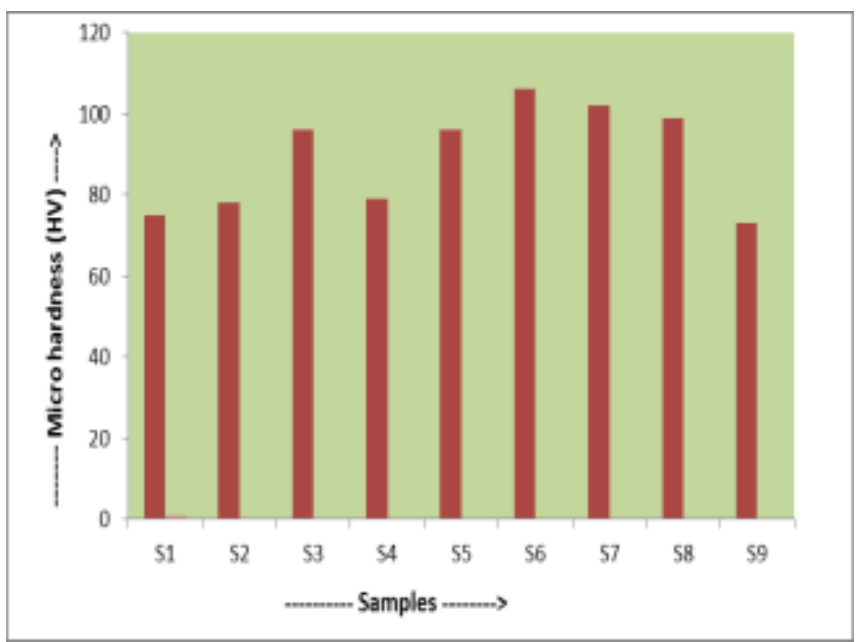

Fig. 9 
Table 3 Hardness of specimens at centres

\begin{tabular}{|c|c|}
\hline Exp no & $\begin{array}{c}\text { Hardness } \\
\text { value ( HV) }\end{array}$ \\
\hline Exp No-1 & 75 \\
\hline Exp No -2 & 78 \\
\hline Exp No -3 & 96 \\
\hline Exp No -4 & 79 \\
\hline Exp No -5 & 96 \\
\hline Exp No -6 & 106 \\
\hline Exp No -7 & 102 \\
\hline Exp No -8 & 99 \\
\hline Exp No -9 & 73 \\
\hline
\end{tabular}

\subsection{Tensile Report}

In general, the $\mathrm{Al}$ surface composites are found to have higher elastic modulus, tensile and fatigue strength over monolithic alloys. In case of heat treatable Al-alloys and their composites, the yield strength of composites increase after heat treatment by reducing the cracking tendency and improving the precipitation hardening. The composites, before fabrication process, are heat treated to an under aged condition as the materials can be shaped more easily and after fabrication, these materials are heat treated to the peak aged condition so as to provide improved mechanical properties. Among many ceramic materials, like $\mathrm{Al}_{2} \mathrm{O}_{3}$ and Tib are widely in use, due to their favourable combination of density, hardness and cost effectiveness. When these reinforcements are combined with $\mathrm{Al}$ alloy, the resulting material exhibits significant increase in its elastic modulus, hardness and wear resistance.

In this the specimens was loaded into a computerized universal testing machine that can apply a load to the specimen at a specific rate by turning a lever. For every $1 \mathrm{~mm}$ deflection the load was determined and the readings were tabulated and continue until the specimen fails. As the specimen is axially loaded in tension at the point of specimen gets elongated and a neck is formed and then the failure occurs variation of ultimate yield strength and ultimate tensile strength of Aluminium alloy and Aluminium /TiB2 composite is shown in Table 4.
Table 4

\begin{tabular}{|c|c|c|c|}
\hline $\begin{array}{c}\text { Exp. } \\
\text { No. }\end{array}$ & $\begin{array}{c}\text { Yield } \\
\text { strength } \\
\text { ( Mpa) }\end{array}$ & $\begin{array}{c}\text { Ultimate Tensile } \\
\text { Strength } \\
(\mathrm{Mpa})\end{array}$ & $\%$ Elongation \\
\hline 1 & 166.2 & 238.8 & $10.45 \%$ \\
\hline 2 & 174.6 & 243.4 & $10.17 \%$ \\
\hline 3 & 172.4 & 255.1 & $10.00 \%$ \\
\hline 4 & 164.7 & 258.7 & $9.50 \%$ \\
\hline 5 & 192.9 & 267.4 & $9.02 \%$ \\
\hline 6 & 223.6 & 285.3 & $8.24 \%$ \\
\hline 7 & 194.2 & 267.2 & $9.22 \%$ \\
\hline 8 & 161.5 & 259.3 & $9.30 \%$ \\
\hline 9 & 186.1 & 272 & $8.50 \%$ \\
\hline
\end{tabular}

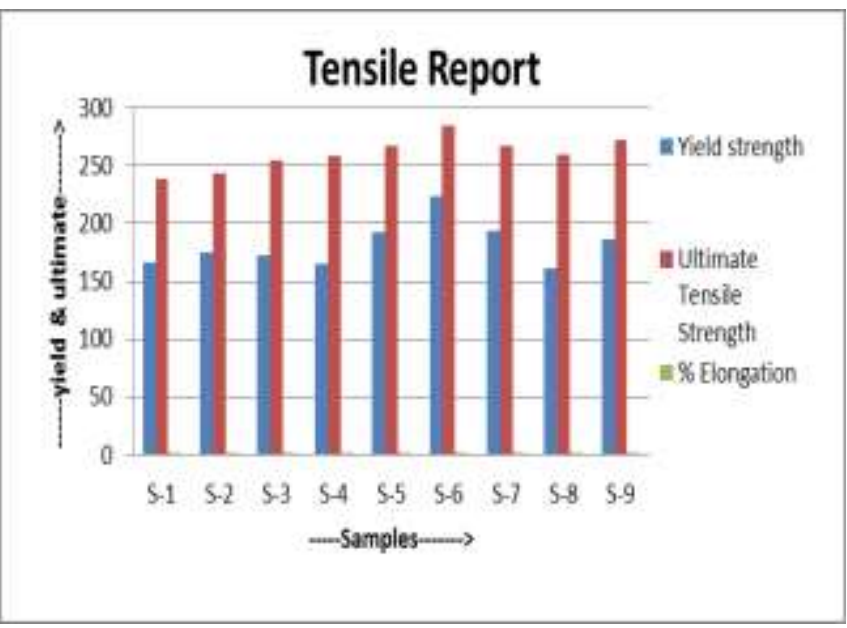

It is observed that composite shows decrease in properties of ultimate tensile strength, yield strength and elongation when compared with unreinforced alloy. Basically tensile properties of composite material are a strong function of nature properties of reinforced particles and matrix alloy. The fine size and shape of the reinforcement also contributed to decrease in tensile strength and yield strength of composite due to incorporation of non deformable Tib2.

\section{CONCLUSIONS}

In the present study, AA 6061 aluminium alloy base surface hybrid composites with Tib2 reinforcement particles were successfully fabricated by using FSP. The microstructure, micro hardness and tensile behaviour were evaluated observing the matrix grains and dispersion of the reinforcement particles. The Following results were obtained: 
1. It has been demonstrated that FSP was an appropriate method to modify the microstructure and mechanical properties of $6061 \mathrm{Al}$-alloy.

2. In general, FSP decreased the grain size and increased the hardness of processed-material. 3. FSP treatments improve the formability of plain samples; hence they could be used for super plastic applications.

4. The micro hardness of the Tib2 added composites surface increases significantly with increasing rotation speed. The hardness value of Aluminium with Tib2 (about HV 100) surface hybrid composites were increased as compared with the average hardness of about HV 106 of the aluminium matrix due to the presence of hard reinforcement particles.

5. The high microhardness of $\mathrm{Al} / \mathrm{Tib} 2$ composite can be attributed to the presence of reinforcement particles, which also improved

the tensile strength.

6. With further research efforts and increased understanding, FSP could be conducted for mechanical behaviour of these composites, like fatigue and creep response and new tool design for uniform distribution of reinforcement particles into the matrix materials.

7. Increased rotation speed and low travelling speeds caused more heat input which affects the thickness of the surface layer, grain size and distribution of the precipitates and reinforcing particles.

8. Good dispersion of Tib2 can be obtained for the composite layer produced by $\omega=800 \mathrm{rpm}$ and $v=$ $15 \mathrm{~mm} / \mathrm{min}$.

9. Good interfacial conditions between particles and base metal can be formed during this solidstate process which avoids the chemical reactions on the interface.

10. Tensile properties are decreased as compared to the base material due to the presence of reinforcement particles which make the matrix brittle.

\section{REFERENCES}

1. "Influence Of Addition Of $\mathrm{Grp} / \mathrm{Al}_{2} \mathrm{O}_{3}$ With Sic On Wear Properties Of Aluminium
Alloy 6061-T6 Hybrid Composites Via

Friction Stir Processing" by A.

DEVARAJU, A. KUMAR, B. KOTIVEERACHARI

2. Department of Mechanical Engineering, National Institute of Technology, Warangal, A.P., India

3. "The Influences of The Friction Stir Processing On The Microstructure And Hardness Of Al 6061 Aluminium

4. Sheet Metal" by T. Prakash1 and P. Sasikumar2 1Asst. Prof (Sr. Grade) and 2Professor Department of Mechanical Engineering 2KPR Institute of Engineering and Technology, Coimbatore

5. Wear and mechanical properties of 6061T6 aluminum alloy surface hybrid composites $\left[(\mathrm{SiC}+\mathrm{Gr})\right.$ and $\left(\mathrm{SiC}+\mathrm{Al}_{2} \mathrm{O}_{3}\right)$ fabricated by friction stir processing Devaraju Aruria, Kumar Adepua, Kumaraswamy Adepub, Kotiveerachari Bazavadaaa Department of Mechanical Engineering, National Institute of Technology, Warangal, India.

6. Shafiei ZA, Rashani Bozorg SF, Zarei H. Microstructure and mechanical properties of $\mathrm{Al} / \mathrm{Al}_{2} \mathrm{O}_{3}$ surface nano-composite layer produced by friction stir processing. Mater Sci Eng A2009;500: 84-91.

7. Surface modification of aluminium by friction stir processing Adem Kurta, Ilyas Uygurb, Eren Cetec a Gazi University, Technical Education Faculty, 06500, Ankara, Turkey Duzce University, Faculty of Engineering, 1620, Duzce, Turkey.

8. GUPTA $\mathrm{M}$, MOHAMED $\mathrm{F} A$, LAVERNIA E J. Solidification behavior of $\mathrm{Al}-\mathrm{Li}-\mathrm{SiCp}$ MMCs processed using variable

9. Co-deposition of multi-phase materials. Materials and Manufacturing Processes, 1990, 5(2): 165-196.

10. "Friction Stir Processing Of AA6061 -A Study" Midhun Antony1, Bijin T Pavithran2, Issac Thamban3 1,2,3M A College Of Engineering, Kothamangalam 
11. "Influence Of Weld-Process Parameters On The Material Characterization Of The Friction-Stir-Welded Joints Of The Aa6061T6 Aluminium Alloy", Hiralal Patil1, Sanjay Soman2 1department Of Mechanical Engineering, Abrama-Navsari, India 2department Of Metallurgy \& Material Engineering, Faculty Of Engineering \& Technology, M. S. University Of Baroda, India 